\title{
Balanced Shh signaling is required for proper formation and maintenance of dorsal telencephalic midline structures
}

\author{
Diana S Himmelstein ${ }^{1 \dagger}$, Chunming Bi ${ }^{1 \dagger}$, Brian S Clark ${ }^{1,2}$, Brian Bai ${ }^{3}$, Jhumku D Kohtz ${ }^{1 *}$
}

\begin{abstract}
Background: The rostral telencephalic dorsal midline is an organizing center critical for the formation of the future cortex and hippocampus. While the intersection of WNTs, BMPs, and FGFs establishes boundaries within this critical center, a direct role of Shh signaling in this region remains controversial. In this paper we show that both increased and decreased Shh signaling directly affects boundary formation within the telencephalic dorsal midline.

Results: Viral over-expression of Shh in the embryonic telencephalon prevents formation of the cortical hem and choroid plexus, while expanding the roof plate. In a transgenic model where cholesterol-lacking ShhN is expressed from one allele $(S h h N /+)$, genes expressed in all three domains, cortical hem, choroid plexus and roof plate expand. In Gli1/2 - - mutant brains, where Shh signaling is reduced, the roof plate expands, again at the expense of cortical hem and plexus. Cell autonomous activation of Shh signaling in the dorsal midline through Gdf7-driven activated Smoothened expression results in expansion of the Wnt3a-expressing cortical hem into the plexus domain. In addition, developmental stage determines dorsal midline responsiveness to Shh.
\end{abstract}

Conclusions: Together, these data demonstrate that balanced Shh signaling is critical for maintaining regional boundaries within the dorsal midline telencephalic organizing center.

\section{Background}

The telencephalic dorsal midline contains two organizing centers: the roof plate and cortical hem $[1,2]$. The roof plate is initially induced by signals from the overlying epidermal ectoderm, and once established, provides a secondary source of secreted TGF $\beta$-family members along the entire dorsal midline of the developing neural tube [3]. Fate-mapping experiments show that the roof plate is derived from Wnt1-expressing cells in the overlying neuroectoderm, and develops from lineagerestricted cellular compartments [4]. Evidence that the roof plate may be an organizer stems from genetic ablation experiments demonstrating roof plate-dependent dorsal interneuron specification in the spinal cord, and cortical and choroid plexus development in the

\footnotetext{
* Correspondence: j-kohtz@northwestern.edu

† Contributed equally

'Developmental Biology and Department of Pediatrics, Children's Memorial Research Center and Feinberg School of Medicine, Northwestern University, Chicago, IL, USA

Full list of author information is available at the end of the article
}

telencephalon [5-7]. In addition, it has been shown that the roof plate directs choroid plexus formation through a cell non-autonomous mechanism [5]. The cortical hem, originally identified as an embryonic structure marked by Wnt expression [8], exhibits hippocampal organizer activity [9]. Targeted inactivation of Wnt3a and the signaling co-factor Lef-1 confirm the hem's role in hippocampal growth and development $[10,11]$.

The intersection of multiple secreted factors expressed in the telencephalic midline are known to contribute to the patterning of this region. These include BMPs, WNTs and FGFs [12-14]. FGF signals from the rostral forebrain regulate anterior-posterior regionalization in the telencephalon [15]. The current model suggests that a number of FGFs, specifically FGF8, function to coordinate the competing morphogenic signals expressed from the dorsal and ventral midlines [16].

However, recent questions have been raised as to a direct role of the secreted signaling protein Shh in patterning the dorsal telencephalic midline. While Shh is expressed in the ventral telencephalic midline as early as

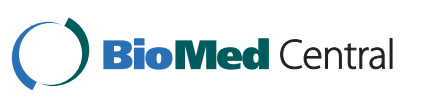


E10.5, a time when the first invagination of the dorsal midline region occurs, it is not detectable in the dorsal telencephalic midline. However, disruption of Shh signaling through mutation of Shh or its downstream targets affects dorsal midline patterning in both humans and mice [17-19]. Genetic interactions between Shh and Gli3 suggested a mechanism [20] whereby Shh expression in the telencephalic ventral midline represses the transcriptional repressor Gli3 through an activity gradient [21]. However, loss of both Shh copies in Gli3 mutants fails to rescue telencephalic dorsal midline defects, challenging the idea that Shh acts solely through a Gli3-dependent mechanism [22]. Together these data suggest that the role of Shh in dorsal telencephalic midline patterning is still not well understood.

In this paper we show that Shh expression from the dorsal extent of the zona limitans intrathalamica (ZLI, [23]) is positioned correctly to directly influence gene expression boundaries critical for telencephalic dorsal midline formation, specifically the choroid plexus and cortical hem. Using mouse models that contain increased or decreased Shh activity in the developing forebrain, we show that balanced Shh signaling is required for proper telencephalic dorsal midline development. Further, we show that disruption of FGF signaling does not result in dorsal midline patterning defects resembling the Shh loss- or gain-of-function mouse models, suggesting that Shh signaling in the dorsal midline is not mediated by FGFs. Together, these data support a direct role of Shh in patterning the dorsal telencephalic midline.

\section{Results}

$S h h$ is expressed adjacent to the $L h \times 5$-expressing roof plate domain in the embryonic telencephalon

At E12.5, the telencephalic dorsal midline is delineated by three regions based on morphology and gene expression [8]: the Wnt3a-expressing cortical hem, the rTTRexpressing choroid plexus, and the $L h \times 5$-expressing roof plate (Figure 1). At E10.5, prior to the appearance of $r T T R$ in the choroid plexus, Wnt $3 a$ and $L h x 5$ overlap in the dorsal midline (Figure 1A, C). Between E11.5 and E12.5, the appearance of the choroid plexus divides the roof and hem boundaries from each other (Figure 1E-G, I-K). In E10.5-E12.5 coronal sections, Shh expression is restricted to telencephalic ventral midline, and therefore unlikely to directly influence formation of dorsal telencephalic midline structures (Figure 1D, H, L). However, sagittal analyses at these stages show that dorsal diencephalic extension of Shh in the ZLI is adjacent to the Lhx5-expressing telencephalic roof plate, the region known to be a telencephalic dorsal midline organizer (Figure 1O, P, S, T). The latter raises the possibility that Shh signaling directly influences dorsal midline structures/boundaries during the time that the choroid plexus becomes juxtaposed between the cortical hem and roof plate.

\section{Increased Shh signaling changes telencephalic dorsal midline morphology and boundaries}

In order to directly test the influence of Shh on dorsal midline development, we used ultrasound image-guided injections to introduce viruses expressing cholesterollacking Shh (ShhN) and full length Shh (wtShh) into the E9.5 embryonic forebrain ventricle. This technique provides a powerful approach to disentangle the spatial and temporal roles of Shh in brain development. At E12.5, three days after viral misexpression, wtShh and ShhN virally infected brains are characterized by expanded lateral ventricles and a thinned cortex. The dorsal midline fails to properly invaginate and cortical hem and choroids plexus differentiation is disrupted (Figure 2F, K, 3E, I, 4K, P, 5F, K).

Previous experiments showed that $\mathrm{ShhN}$ in vitro and wtShh in vivo ventralizes the dorsal telencephalon by activating Dlxs and Evfs at embryonic ages [24-28]. Characterization of the E12.5 telencephalon from wtShh and ShhN viral infections performed at E9.5 confirms that cortical tissue is ventralized, expressing $D l \times 2$ (Figure 2H, M), $D l x 5$ (Figure 2I, N) and $E v f_{c}$ (Figure 2J, $\mathrm{O})$. However, the dorsal midline is refractory to ventralization by ectopic Shh expression (Figure 2Q-S). While the dorsal midline is not ventralized by ectopic Shh activation, cortical genes $E m x-1$ and $P a x-6$ are shifted laterally (Emx-1, Figure 3G, K; Pax-6, Figure 3H, L), showing that the dorsal midline has not been transformed to cortical or striatal fate.

Since dorsal midline morphology is significantly altered by Shh activation, it is likely that the dorsal midline is still influenced by Shh signaling. Therefore, we next addressed how genes distinguishing the cortical hem, choroid plexus and roof plate may be altered by Shh activation. Figure 4 shows that Shh activation results in the loss of hem (Wnt3a, Figure 4M, R) and plexus ( $r T T R$, Figure $4 \mathrm{~N}, \mathrm{~S})$ structures. $M s x-1$, which is normally expressed by both hem and plexus, is also lost upon Shh activation (Figure 4O, T). Therefore, Shh activation results in the loss of specific midline structures, but does not transform the dorsal midline to a ventral fate.

We next asked if Shh activates downstream targets in the dorsal midline, or whether the remaining dorsal midline tissue is refractory to Shh signaling. Figure 5 shows that the dorsal midline responds to Shh activation by ectopic activation of its transcriptional target Gli-1 [29] (Figure 5G, L), its co-receptor Ptc-1 [30-32] (Figure $5 \mathrm{I}, \mathrm{N})$, and expansion of the roof plate domain marked by $L h x 5$ expression (Figure 5J, O). Therefore, Shh 


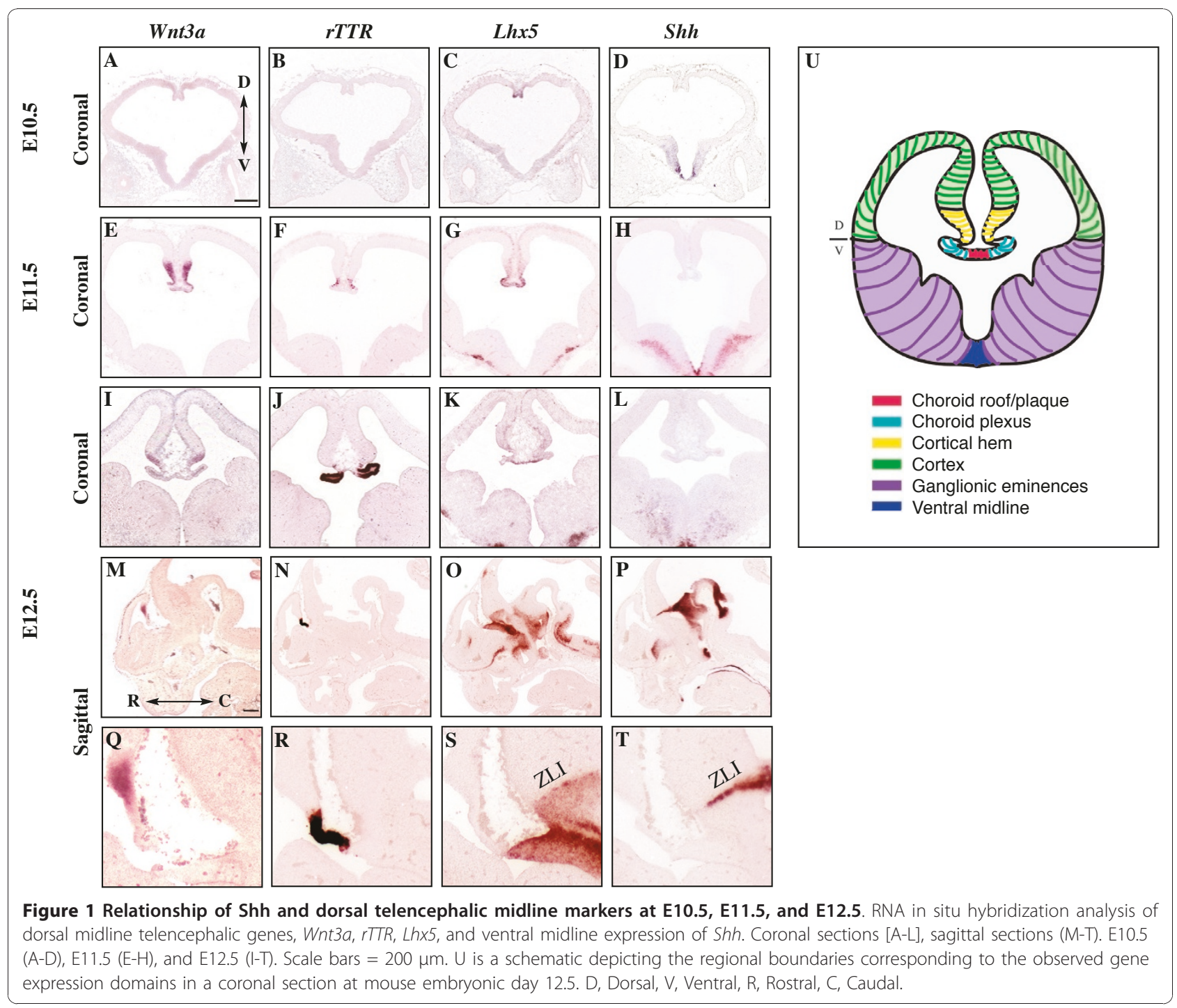

activation causes roof plate expansion at the expense of choroid plexus and cortical hem.

The experiments in Figure 2, 3, 4, and 5 show the effects of ectopic Shh activation by viral delivery to E9.5 telencephalic dorsal midline. In order to address if increased Shh signaling from its normal source (ventral midline or ZLI) would affect telencephalic dorsal midline formation, we utilized an activated Shh transgenic model where one allele of Shh is replaced by ShhN $(S h h N /+)$ [33]. In this model, $S h h N$ is proposed to travel further, resulting in Shh activation in the dorsal telencephalon. Figure 6 shows that all three telencephalic dorsal midline boundaries are expanded in $\mathrm{ShhN/+}$ mice (Figure 6D-F). While viral activation and genetic modification both cause roof plate $L h x 5$ expansion, $r T T R$ and Wht $3 a$ expand in ShhN/+ mice (Figure 6) and are absent in brains injected with Shh virus (Figure 4). Together, these data not only support the idea that increased Shh signaling alters telencephalic dorsal midline patterning, but that timing and dose are critical factors in determining the outcome.

\section{Telencephalic dorsal midline defects result from decreased Shh signaling}

Increased Shh signaling, both indirectly through loss of a repressor (Gli3, [8]) and directly through transgenic or viral expression (this paper) can affect telencephalic dorsal midline boundaries. However, it is unknown whether Shh normally plays a direct role in patterning the telencephalic dorsal midline. The dramatic loss of both dorsal and ventral telencephalic midline structures in Shh -/- mutants supports the idea that Shh is critical for proper formation of both regions [34]. Since Shh has been shown to activate transcriptional targets through the action of Gli1 and Gli2, combined loss of these two transcription factors reduces, but does not eliminate 


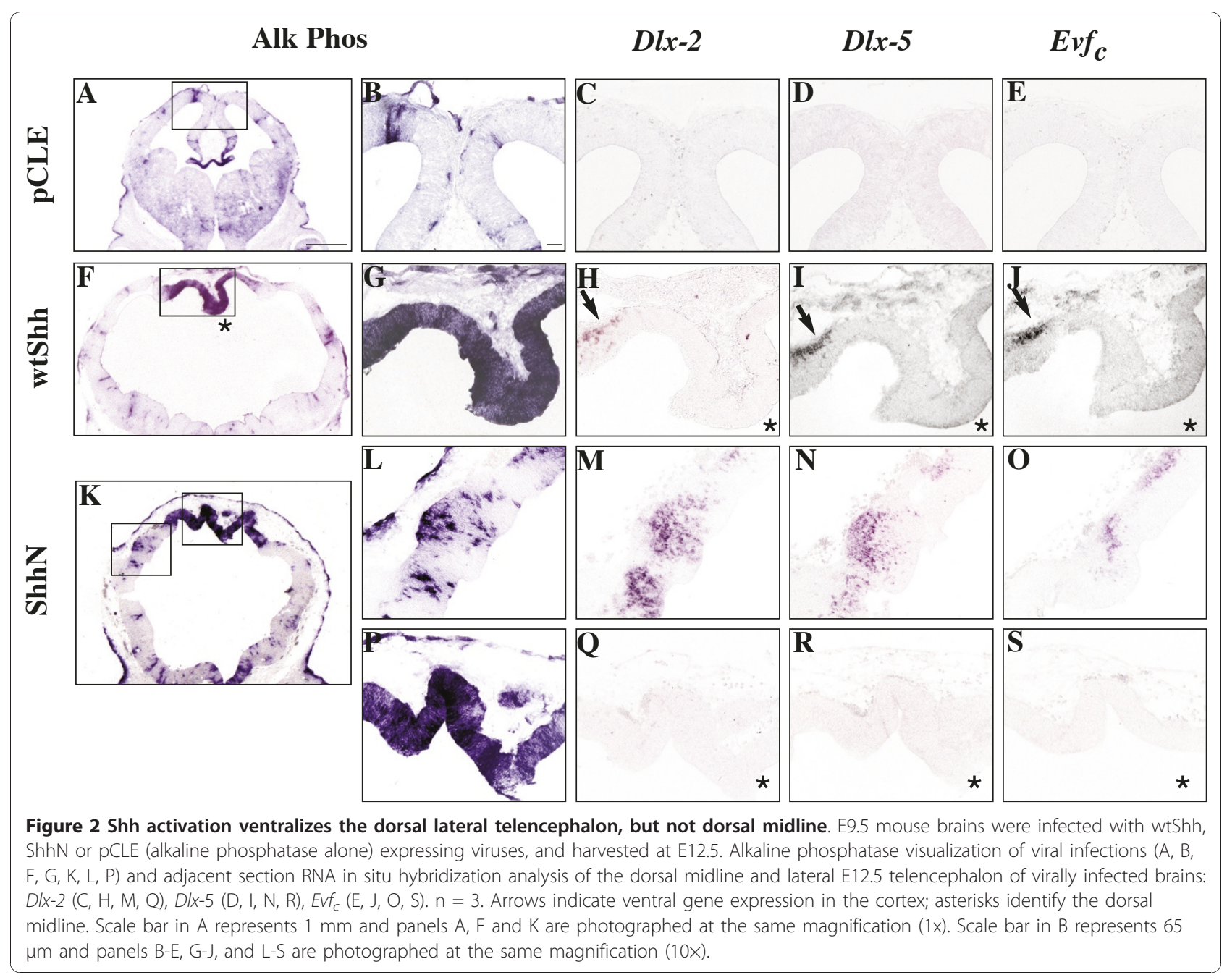

direct Shh signaling [35,36]. Figure 7 shows that reduced Shh signaling in Gli1/2 -/- mutants results in the loss of Wnt3a (Figure 7D) and rTTR (Figure 7E) in the hem and plexus, respectively. In place of the hem and plexus, the Gli1/2 - /- mutant telencephalic dorsal midline now expresses $L h x 5$ throughout (Figure 7F), without proper thinning to a single epithelial layer characteristic of the roof plate [1]. This suggests that Shh signaling is required for inducing proper morphology and gene expression boundaries that establish the hem, plexus and roof relationships.

The current model predicts that Shh indirectly influences dorsal midline development through the action of FGF8 $[18,33]$. Shh expression from the ventral midline is necessary for the maintenance of FGF8 expression [37], and FGF8 is thought to restrict the spread of BMPs and WNTs in the dorsal telencephalon [12]. Given the hypothesis that Shh acts through FGF8 to influence the dorsal midline, we investigated the effects of FGF inhibition during dorsal telencephalic midline patterning. An FGF receptor tyrosine kinase inhibitor (PD173074, Calbiochem) was injected into mouse E9.5 forebrain, and gene expression changes were examined at E12.5. While the FGF inhibitor interferes with the morphological development of the dorsal midline, Wnt3A and rTTR are still expressed in the cortical hem and choroid plexus structures, respectively (Figure 7G, H). In addition, $L h \times 5$ expansion and thickening of the roof plate is not observed (Figure 7I). Therefore, the dorsal midline defects resulting from reduced Shh signaling (Gli1/2 -/-) are distinct from reduced FGF signaling, raising the possibility that Shh signaling in the telencephalic dorsal midline may be independent of FGF. However, we cannot rule out the possibility that FGF inhibition is incomplete, and then fails to generate the complete roof plate phenotype. Future experiments that include both gain and loss of function FGF action in the telencephalon combined with Shh activation will be necessary to determine whether Shh acts through FGF in this region. 


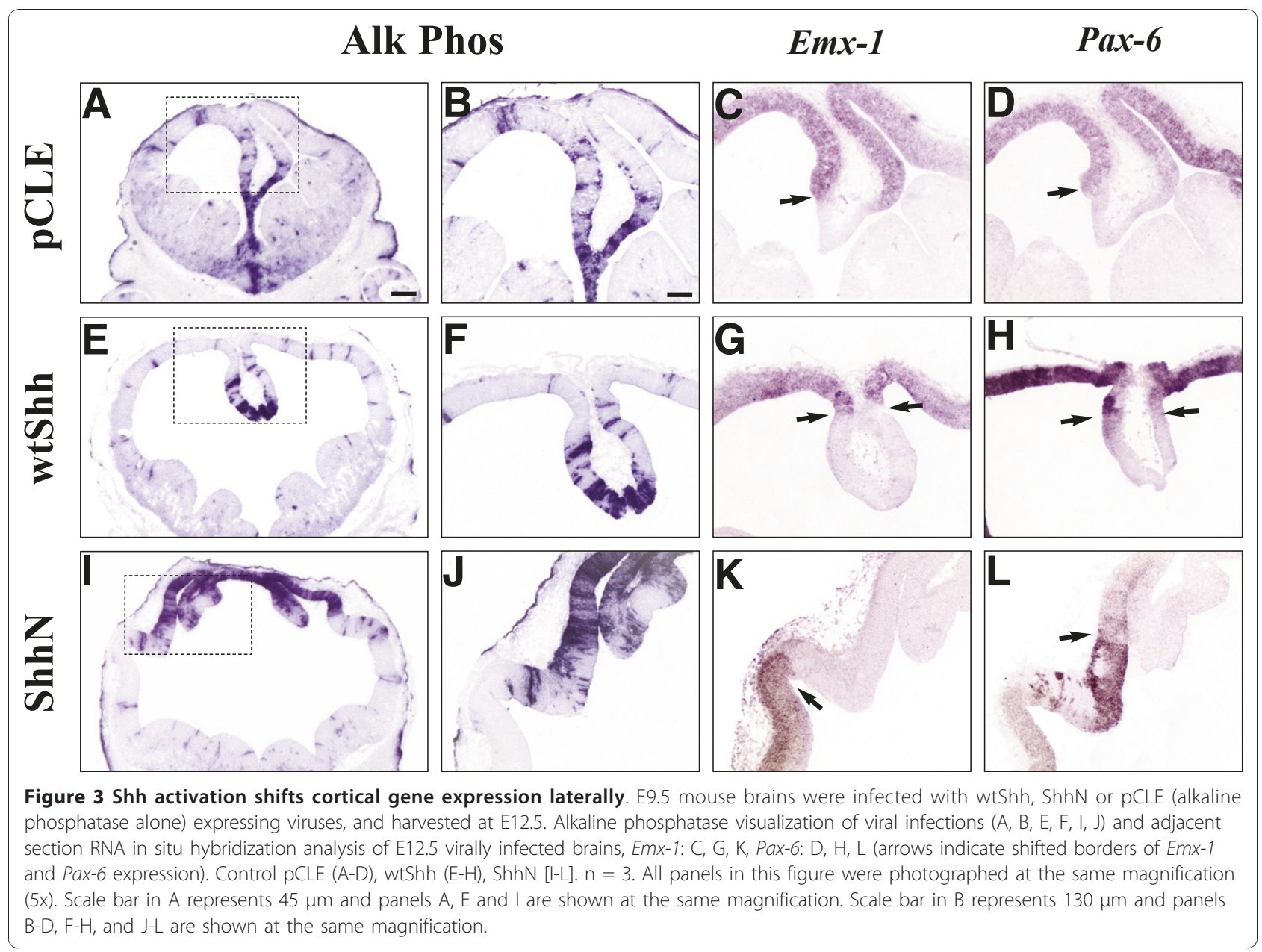

Cell autonomous increase in telencephalic dorsal midline Shh signaling alters cortical hem/plexus boundary

In order to distinguish between cell-autonomous and non-autonomous Shh activity, we next tested the effects of Gdf7-promoted activated Smoothened on telencephalic dorsal midline gene expression boundaries and morphology. Using a Gdf7cre transgenic mouse [6] crossed to a conditionally activated Smoothened (ActSmo) [38], it is possible to limit Shh activation to roof plate cells, and to a small group of hem and plexus cells. Figure 8 shows that cell autonomous activation of Shh through act-Smo expression in the Gdf7 domain increases roof plate thickness, and prevents formation of the single epithelial layer characteristic of the roof plate [1]. Wnt $3 a$, which is normally limited to the cortical hem, expands into the choroid plexus region (arrows, Figure 8D). In addition, $r T T R$ expression expands slightly dorsally into the cortical hem region (arrows, Figure $8 \mathrm{E}$ ), and the choroid plexus appears somewhat reduced in size. Together these data suggest that Shhdependent cell autonomous changes in the roof plate shifts boundaries between hem and plexus.
Time-dependent effects of Shh ectopic activation on dorsal midline boundaries

The appearance of the telencephalic choroid plexus (between E11.5 and E12.5) follows the formation of the roof plate and cortical hem (between E9.5 and E11.5). The appearance of Shh in the ZLI occurs between E10.5 and E12.5 [39]. If balanced Shh signaling were required to maintain relationships between the telencephalic roof plate, hem, and plexus, then it would be expected that the roof plate remains competent to respond to Shh signaling later than E9.5. Therefore, we next asked whether increased Shh signaling affects dorsal midline patterning after roof plate and hem formation have already begun. Figure 9 shows E12.5 dorsal telencephalic midline analysis of brains infected with wtShh virus at E10.5. Roof plate expansion, as indicated by $L h x 5$ expression, is still observed (Figure 9B). In addition, the choroid plexus gene $r T T R$ is not detected rostrally in the telencephalon (Figure 9E), but is detected in more caudal sections at the level of the diencephalon (Figure 9H). The morphological invagination of the choroid plexus epithelium is apparent without induction of $r T T R$. The cortical hem 


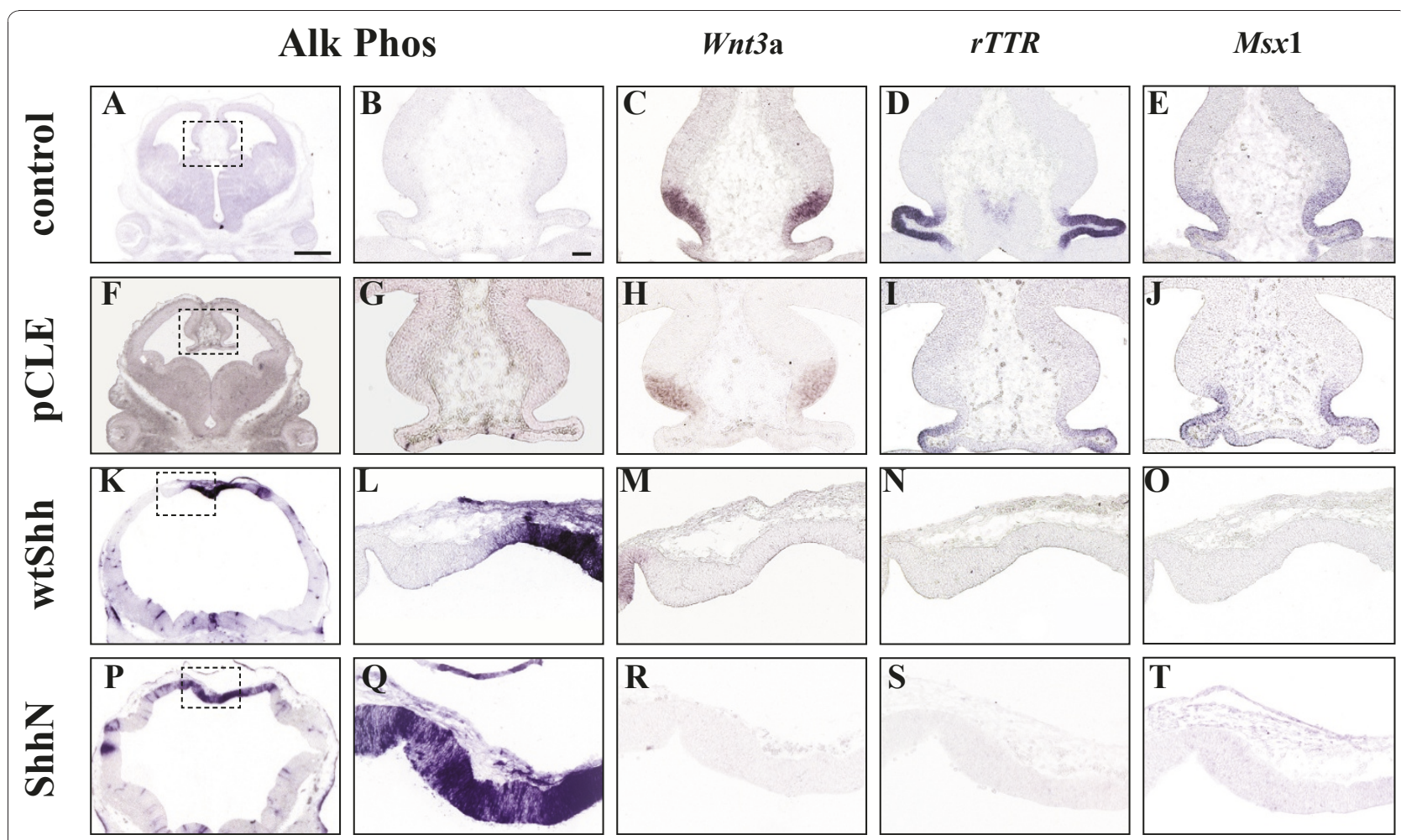

Figure 4 Shh activation prevents cortical hem and choroid plexus formation. E9.5 mouse brains were infected with wtShh, ShhN, and pCLE (alkaline phosphatase alone) expressing viruses, or uninfected littermate control (control), and harvested at E12.5. Alkaline phosphatase visualization of viral infections ( $A, B, F, G, K, L, P, Q$ ) and adjacent section RNA in situ hybridization analysis of the dorsal midline of E12.5 virally infected brains, Wnt3a (cortical hem): C, H, M, R. rTTR (choroid plexus): D, I, N, S, Msx1 (cortical hem + plexus): E, J, O, T. $n=3$. Scale bar in A represents $1 \mathrm{~mm}$ and panels $\mathrm{A}, \mathrm{F}, \mathrm{K}$ and $\mathrm{P}$ are photographed at the same magnification (1X). Scale bar in B represents $65 \mu \mathrm{m}$ and panels B-E, G-J, L-O and Q-T are photographed at the same magnification (10X).

can be distinguished both morphologically and by expression of Wnt3A (Figure 9C, F, I). Expansion of the hem into the plexus domain is also observed (Figure 9F, I), similar to that found in GDF7cre-ActSmo brains (Figure 8D). Therefore, hem and plexus structures change in Shh responsiveness between E9.5 and E10.5, while the roof plate retains its earlier sensitivity. The latter is consistent with the idea that Shh is important for maintaining the roof plate after its formation.

\section{Discussion}

In this paper, we show that increased or decreased Shh signaling disrupts dorsal telencephalic midline development, suggesting that balanced Shh signaling is required for the proper formation and maintenance of the telencephalic dorsal midline. We show that Shh activity can directly influence dorsal midline patterning through ectopic viral expression at E9.5 (Shh ${ }^{\text {E9.5vir }}$ ). The Shh ${ }^{\text {E9.5- }}$ vir telencephalon lacks both cortical hem and choroid plexus. In addition, the $\mathrm{Shh}^{\mathrm{E} 9.5 \mathrm{vir}}$ telencephalic dorsal midline is refractory to ventralization, with expanded expression of the roof plate gene $L h \times 5$. Recent characterization of the $S h h N /+$ telencephalon also shows $L h x 5$ roof plate expansion accompanied by a loss of cortical hem and choroid plexus [33]. These results are consistent with the finding that $\mathrm{ShhN}$, the cholesterol lacking form of Shh, is more potent in telencephalic explant assays [25], and exhibits an extended range of signaling $[33,40,41]$. Also consistent with this idea is that ectopic expression of ShhN in the dorsal midline results in a more extreme phenotype than wtShh (Figure $2 \mathrm{~F}$ vs $2 \mathrm{~K}$, Figure $3 \mathrm{E}$ vs $3 \mathrm{I}$, Figure $4 \mathrm{~K}$ vs $4 \mathrm{P}$, Figure $5 \mathrm{~F}$ vs $5 \mathrm{~K}$ ). While our analysis of Shh ${ }^{\text {E9.5vir }}$ using wtShh or ShhN supports that $S h h N /+$ mutant phenotypes in the telencephalon result from increased Shh activity, our analysis of ShhN/+ dorsal midline defects differs from that of Huang et al. [33]. Both analyses show that $S h h N /+$ mutants exhibit roof plate expansion. However, unlike Huang et al. [33], our analysis shows that ShhN/+ mutants display expanded cortical hem and plexus structures along with the expanded roof plate, generating a larger dorsal midline. Phenotypic differences in ShhN/+ may result from differential cre-induced removal of the ShhN conditional allele (EIIAcre compared with Sox $2 \mathrm{Cre}$ ), or possibly from mouse strain differences. 

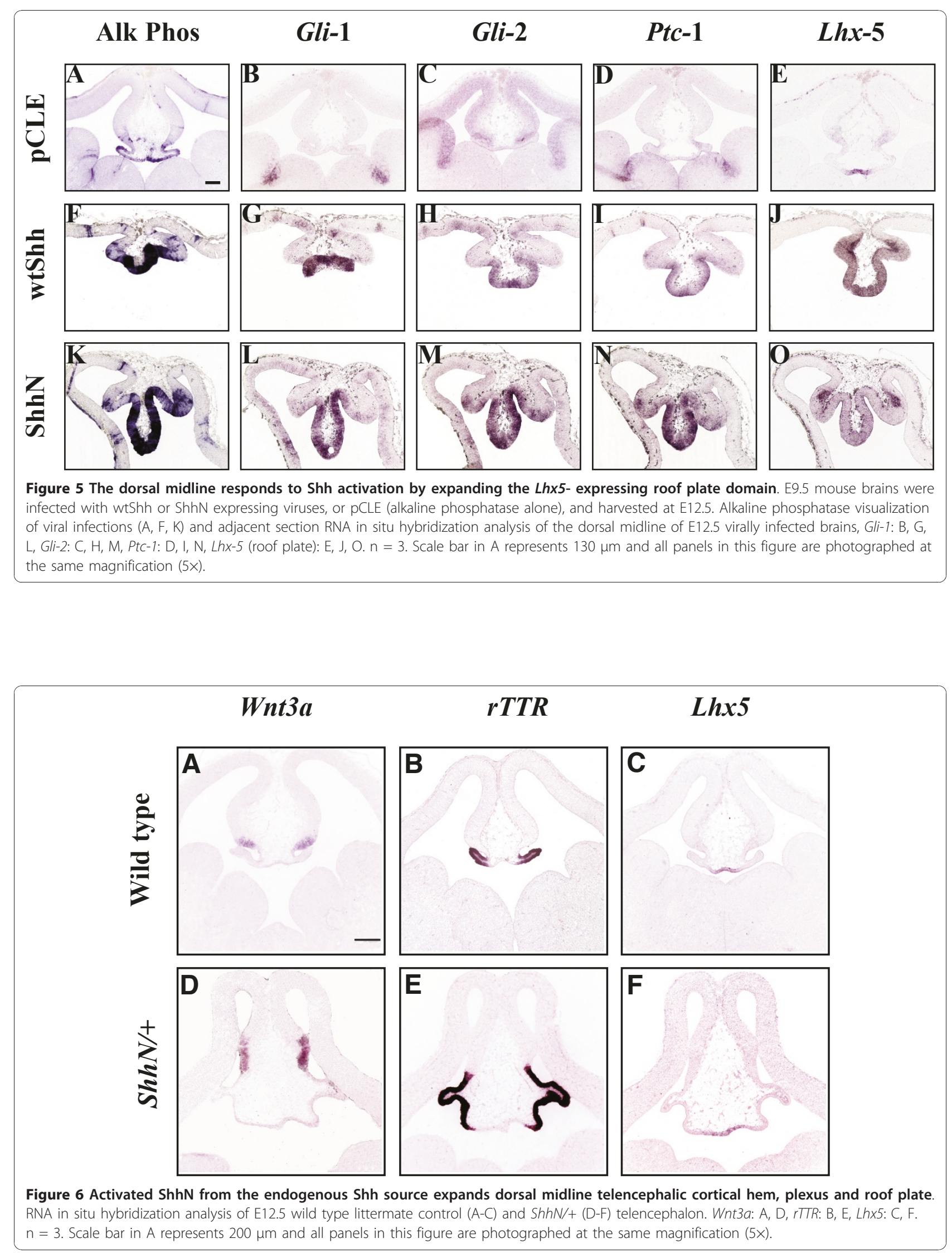


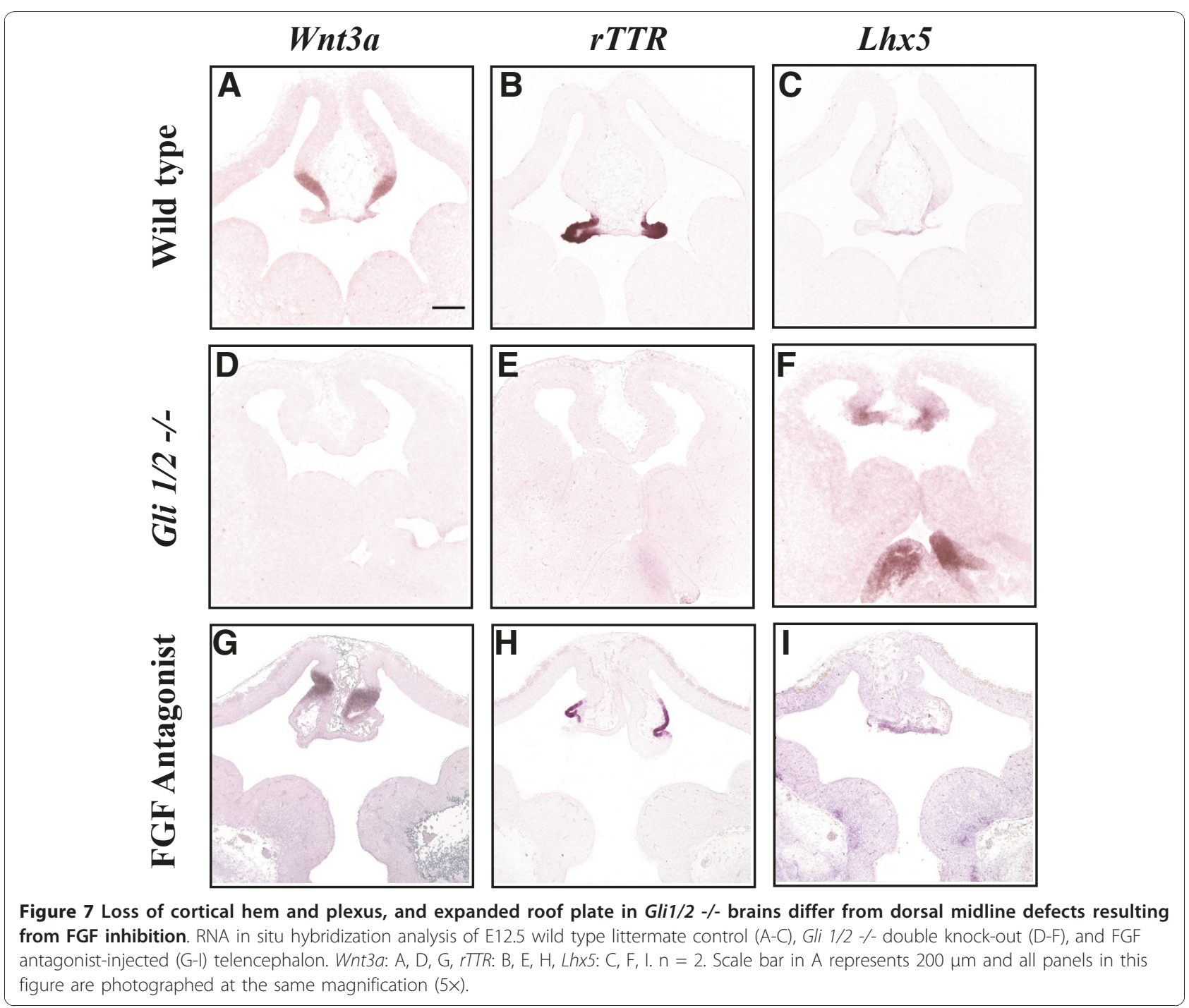

The source of Shh in ShhN/+ mutants derives from adjacent or ventral domains. The dorsal midline expansion in $S h h N /+$ embryos may be attributed to increased Shh signaling from the ventral telencephalon, increased signaling from the diencephalic ZLI, or both. In contrast, viral delivery results in direct expression of Shh in the dorsal midline. Thus, the level of exposure at the dorsal midline is likely to be higher in Shh ${ }^{\mathrm{E} 9.5 \mathrm{vir}}$ compared with $S h h N /+$. The use of viral delivery methods can help elucidate direct effects of Shh activity on dorsal midline boundary formation. Another important difference between these two methods of ectopic Shh expression is the timing of delivery. In Shh ${ }^{\text {E9.5vir }}$, ectopic Shh activity begins at E9.5, after the telencephalon has begun to form. In ShhN/+, increased Shh is co-expressed with endogenous Shh concurrent with formation of the telencephalon. These data suggest that the ability of Shh to prevent or expand cortical hem and plexus may be determined by changes in source, level, or timing of exposure to Shh.

In a direct test of the effect of timing of Shh exposure on dorsal midline patterning, Shh viral infections were performed at E10.5 (Shh ${ }^{\text {virE10.5 }}$ ). Several interesting differences are detected when dorsal midline patterning is compared in Shh ${ }^{\text {virE9.5 }}$ and Shh ${ }^{\text {virE10.5 }}$ brains. While the roof plate expands in response to Shh at both delivery time points, opposite effects occur on the hem, which expands after E10.5 Shh exposure rather than diminishing (E9.5). In the Shh ${ }^{\text {virE10.5 }}$ telencephalon, morphological appearance of the choroid plexus occurs without activation of the plexus-specific gene $r T T R$, suggesting that choroid plexus development is still sensitive to Shh activity at this time. Differential alteration of dorsal midline patterning as a result of different methods of increased Shh activity supports the idea that the dorsal 


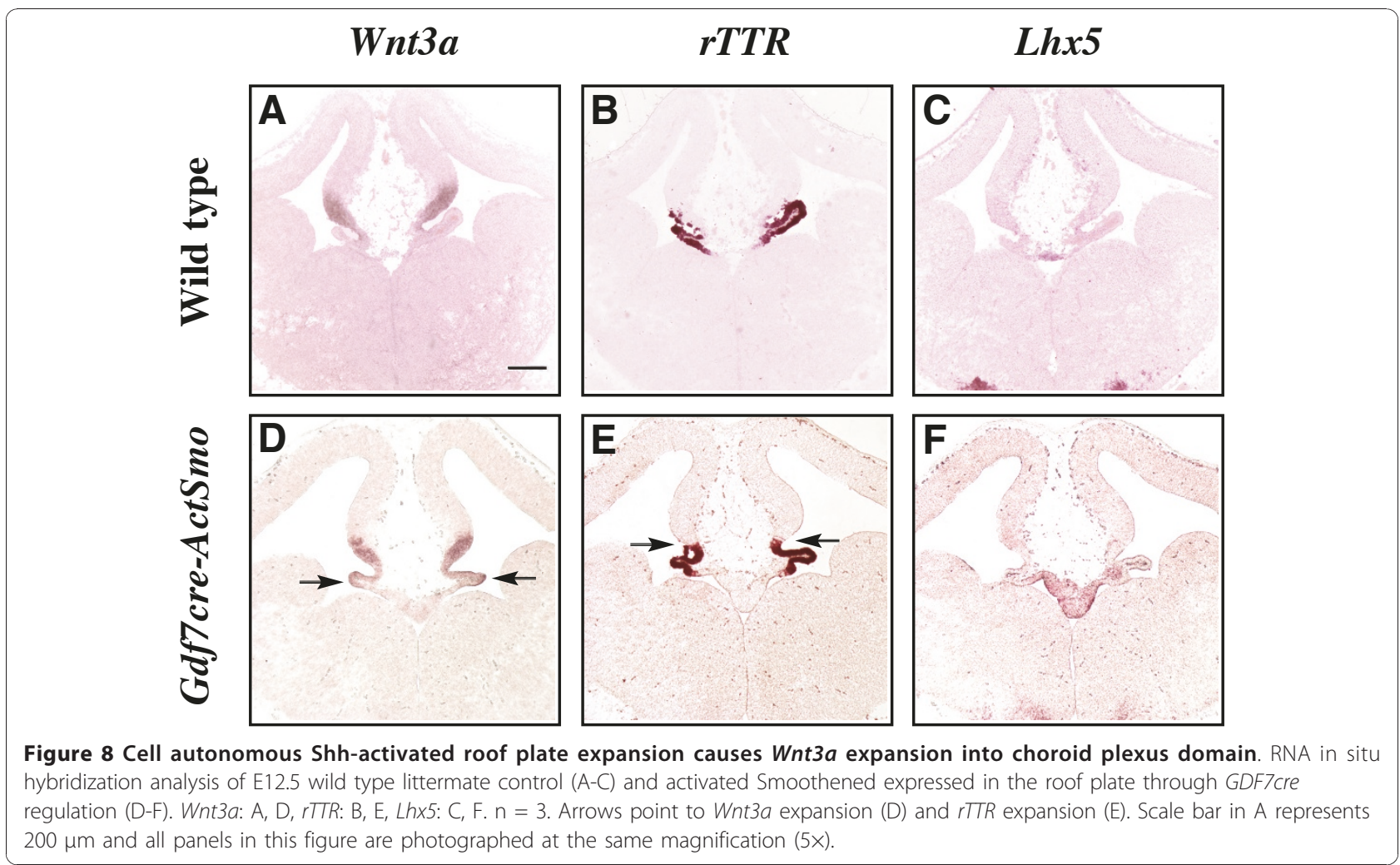

midline, and particularly the roof plate, is a sensitive responder of Shh signaling.

It has previously been proposed that Shh influences dorsal telencephalic midline patterning through a Gli3 gradient or FGF signaling rather than through direct signaling $[21,22,33]$. However, the sensitivity of the dorsal telencephalic midline to ectopic Shh signaling suggests that Shh can directly influence patterning of this region. In addition, decreased Shh signaling in mice lacking both Gli1 and Gli2 results in dorsal telencephalic midline defects similar to that found when Shh is increased $\left(\mathrm{Shh}^{\mathrm{E} 9.5 \mathrm{vir}}\right)$ : loss of cortical hem and choroid plexus, with a concomitant expansion of the roof plate gene Lhx5. Therefore, both increased and decreased Shh signaling can have similar effects on telencephalic dorsal midline patterning.

A shared aspect between Gli1/2 -/- mutants, Shh ${ }^{\text {E9.5vir, }}$ Shh ${ }^{\text {E10.5vir }}$ and $S h h N /+$ is $L h \times 5$-expressing roof plate expansion. Cell autonomous Shh activation in the roof plate (GDF7cre-ActSmo) also results in roof plate and hem expansion with minimal plexus expansion, supporting a direct role of Shh in maintaining roof plate/hem/ plexus boundaries. These data further support previous data suggesting a cell-non-autonomous role of the roof plate, presumably mediated by BMPs, influencing choroid plexus formation [5]. Together, these data show that the roof plate is particularly sensitive to Shh signaling, requiring a balanced level of Shh activity for proper morphology and gene expression. Interestingly, mutations in Shh or its downstream targets result in the developmental defect holoprosencephaly $[19,42]$, and interference in roof plate function has been linked to a milder form of the disease affecting dorsal hemispheric separation [43-45]. Thus, our data suggests that Shhmediated roof plate effects may be responsible for the dorsal midline defects found in holoprosencephaly.

We show that both increases and decreases in Shh signaling ventrally (ShhN/+ and Gli1/2 -/-) and dorsally (wtShh and ShhN injections) significantly alter dorsal midline gene expression. The current model predicts that Shh acts through FGF8 to influence the telencephalic dorsal midline $[18,33]$. However, the dorsal midline phenotype obtained with reduced FGF signaling and altered Shh signaling may be distinct. In particular, roof plate expansion of $L h \times 5$ is common to both reduced and increased Shh signaling, but absent from reduced FGF signaling. It is possible that the failure to observe common roof plate defects between FGF inhibition and Shh alterations is due to inefficient FGF reduction. However, an argument against this is that the FGF inhibitor increases rather than prevents Wnt3a expression in the hem, as observed with altered Shh signaling. If FGF inhibition is inefficient, the phenotype obtained would be expected to be a subset of the complete phenotype rather than an opposing 


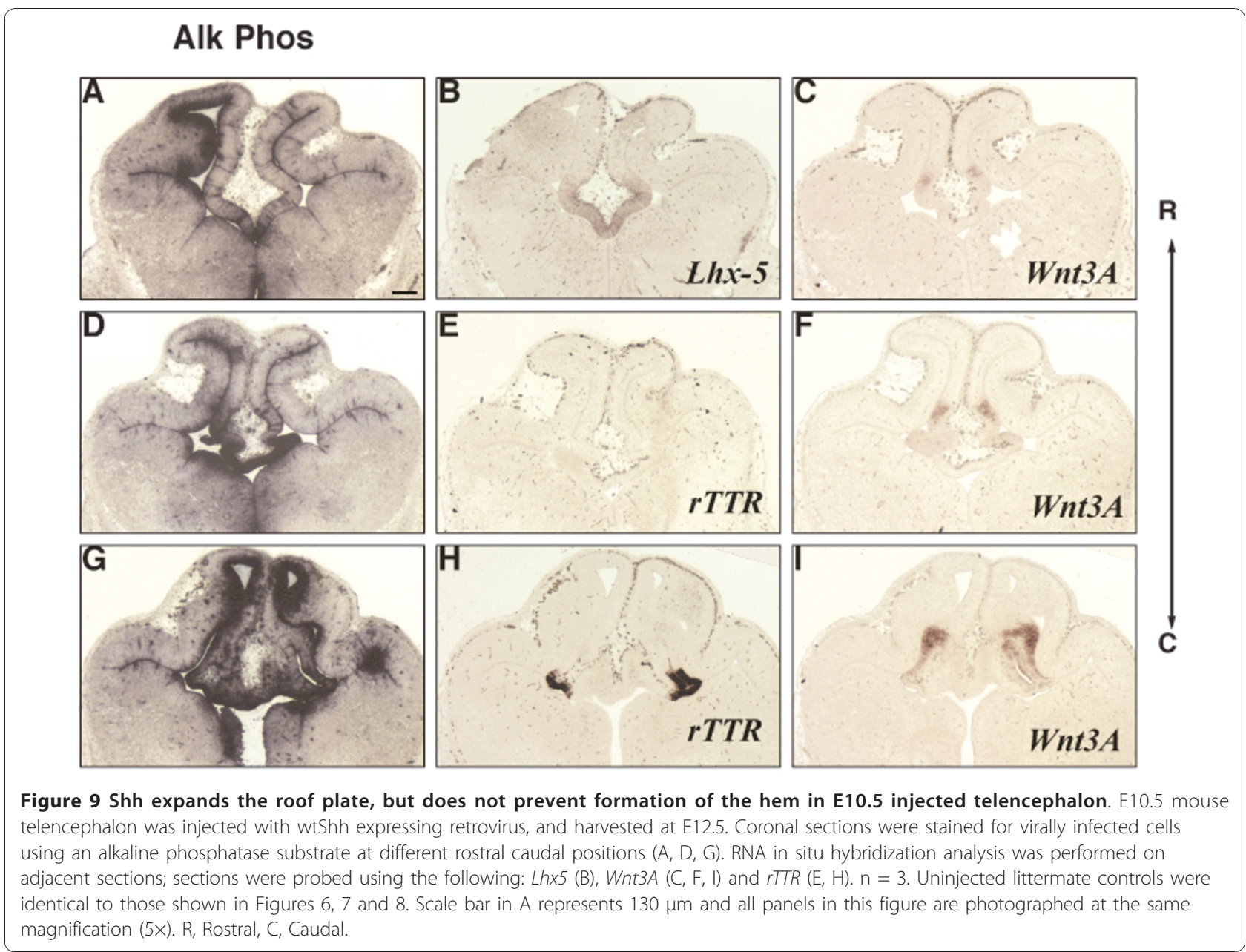

phenotype. Another argument against inefficient FGF inhibition is the appearance of obvious dorsal midline morphological defects in response to the FGF inhibitor. If FGF inhibition were inefficient, gene expression boundaries may be changed without obvious morphological defects. Although further manipulations are necessary to definitively rule out Shh action through FGFs in the dorsal midline, the present data support the idea that Shh acts directly rather than through FGF signaling to maintain boundary relationships in the dorsal telencephalic midline.

Experiments in this paper indicate that the telencephalic dorsal midline, specifically the roof plate, is a direct Shh target. What is the most likely source of Shh that directs telencephalic dorsal midline formation? During the time that mouse telencephalic dorsal midline boundaries are established (E10.5-E12.5), the Lhx5 expression domain in the roof plate becomes juxtaposed to Shh expression in the ZLI. This is most apparent at E12.5 (Figure 1S, T). The ZLI is a strip of cells that act as a signaling center to induce expression of regionally restricted transcription factors in flanking areas $[23,46]$.
The ZLI demarcates the boundary between the prethalamus and the functionally distinct thalamus and a gradient of Shh expression from the ZLI is required for establishing regional identity in these bordering structures [47]. While DiI labeling revealed that the Shhexpressing ZLI initially forms from cells in the alar plate, both Shh expression in the ZLI and subsequent diencephalic development depend on a source of Shh secreted from the basal plate of the forebrain [46]. Taken together with results in this paper, reduced or increased Shh activity resulting from mutations in Shh or its downstream targets would be predicted to affect ZLI formation, and ultimately influence patterning and/ or maintenance of the telencephalic dorsal midline.

\section{Conclusions}

Our data suggests that the telencephalic roof plate is a sensitive responder to changes in Shh activity, and that its expansion occurs in response to increased or decreased Shh signaling. We show that roof plate expansion in response to changes in Shh signaling occurs at the expense 
of the hem and plexus or can lead to expansion of the hem and plexus. In addition, responsiveness of the telencephalic dorsal midline to Shh signaling changes between E9.5 and E10.5 in mice. The structural relationship of Shh and dorsal midline markers raises the possibility that dorsally expressed Shh from the diencephalic ZLI is a source of Shh signaling to the telencephalic dorsal midline. We propose that imbalanced Shh signaling directly changes dorsal midline boundaries between the roof plate, choroid plexus and cortical hem.

\section{Methods}

\section{Animals and Surgery}

ShhN floxed mice [48] were obtained from Dr. A. McMahon, and crossed to EIIAcre mice (Jackson Lab) to generate $S h h N /+$ embryos at E12.5. ActSmo floxed mice [38] were crossed to GDF7cre mice [6] to generate GDF7creActSmo E12.5 embryos. Animals used in these studies were maintained according to protocols approved by Institutional Animal Care and Use Committee at Children's Memorial Hospital Research Center. Timedpregnant Swiss Webster mice used for injections were obtained from Taconic breeding laboratories. Embryonic day 0.5 is defined as noon of the day a vaginal plug was found after overnight mating. Detailed animal care, preparation for surgery and the use of the ultrasound scanner (UBM scanner) have been previously described [49].

\section{Viral expression and embryonic injections}

Shh full-length cDNA (wtShh) and the N-terminal fragment $(\mathrm{ShhN})$ were inserted into the $\mathrm{pCLE}$ viral vector backbone, and pseudo-typed retrovirus was produced as previously described [26]. Viruses were titered on the C17 neural cell line [50]. Western analysis (not shown) on $\mathrm{C} 17$ infected extracts was performed with rabbit anti-Shh antibody (1:5000, R\&D). Viruses were diluted to $5 \times 10^{7} \mathrm{cfu} / \mathrm{ml}$ in PBS containing $80 \mu \mathrm{g} / \mathrm{ml}$ polybrene (Sigma). FGF receptor tyrosine kinase inhibitor PD173074, Calbiochem) was dissolved in DMSO and diluted to $25 \mu \mathrm{M}$ in PBS containing $80 \mu \mathrm{g} / \mathrm{ml}$ polybrene (sigma). FGF receptor tyrosine inhibitor PD173074, calbiochem) was dissolved in DMSO and diluted to $25 \mu \mathrm{M}$ in PBS containing $80 \mu \mathrm{g} / \mathrm{ml}$ polybrene. $1-1.5 \mu \mathrm{l}$ of virus or FGF inhibitor was injected into the E9.5 or E10.5 mouse telencephalon using ultrasound-guided in utero injection, as previously described $[26,49,51]$. Embryos were harvested 2 or 3 days after injection, as indicated.

\section{In situ hybridization}

In situ hybridization was performed by modification of Schaeren-Wiemers and Gerfin-Moser [52] as previously described [27], with the exception of the $r T T R$ probe, which was visualized using the method of Tekki-Kessaris et al. [53]. The $L h x 5$ in situ probe was made from
pGEM-Teasy (Promega) after subcloning an RT-PCR fragment made from E12.5 mouse brain RNA using the following primers:

5' Primer - 5'ACA TGA GGG TCA TTC AGG TGT GGT 3'

3' Primer - 5' TGT GCT TGG AAT CTC GAC CCT TCA 3'

\section{Acknowledgements}

We thank Kathy Millen for helpful discussions, Raj Awatramani. for GDF7creActSmo embryos, and the following investigators for probes: Wnt3A (P. Salinas), rTTR (W. Duan), Msx1 (C. Abate-Shen), Emx1 (E. Boccinelli), Pax-6 (P. Gruss), Dlx-2, Dlx-5 (J. Rubenstein), Gli1, Gli2, Ptc1 (M. Matise). This work was funded by NICHHD RO1 HD044745 and HD056504 and Illinois Excellence in Academic Medicine to J.D.K.

\section{Author details}

'Developmental Biology and Department of Pediatrics, Children's Memorial Research Center and Feinberg School of Medicine, Northwestern University, Chicago, IL, USA. ${ }^{2}$ Department of Cell Biology, Neurobiology and Anatomy, Medical College of Wisconsin, Milwaukee, WI, USA. ${ }^{3}$ Department of Genetics, Case Western Reserve University, Cleveland, OH, USA.

\section{Authors' contributions}

DSH performed experiments and prepared the manuscript. CB and BC performed experiments. BB contributed Gli1/2 -/- embryos. JDK designed experiments and prepared the manuscript. All authors read and approved the manuscript.

Received: 28 June 2010 Accepted: 29 November 2010

Published: 29 November 2010

\section{References}

1. Chizhikov W, Millen KJ: Roof plate-dependent patterning of the vertebrate dorsal central nervous system. Dev Biol 2005, 277:287-95.

2. O'Leary DD, Sahara S: Genetic regulation of arealization of the neocortex. Curr Opin Neurobiol 2008, 18:90-100

3. Liem KF, Tremml G, Jessell TM: A role for the roof plate and its resident TGFbeta-related proteins in neuronal patterning in the dorsal spinal cord. Cell 1997, 91:127-38.

4. Awatramani R, Soriano P, Rodriguez C, Mai JJ, Dymecki SM: Cryptic boundaries in roof plate and choroid plexus identified by intersectional gene activation. Nat Genet 2003, 35:70-5.

5. Currle DS, Cheng X, Hsu CM, Monuki ES: Direct and indirect roles of CNS dorsal midline cells in choroid plexus epithelia formation. Development 2005, 132:3549-59.

6. Lee K, Dietrich P, Jessell TM: Genetic ablation reveals that the roof plate is essential for dorsal interneuron specification. Nature 2000, 403:734-40.

7. Monuki ES, Porter FD, Walsh CA: Patterning of the dorsal telencephalon and cerebral cortex by a roof plate-Lhx2 pathway. Neuron 2001, 32:591-604.

8. Grove EA, Tole S, Limon J, Yip L, Ragsdale CW: The hem of the embryonic cerebral cortex is defined by the expression of multiple Wnt genes and is compromised in Gli3-deficient mice. Development 1998, 125:2315-25.

9. Mangale VS, Hirokawa KE, Satyaki PR, Gokulchandran N, Chikbire S, Subramanian L, Shetty AS, Martynoga B, Paul J, Mai MV, et al: Lhx2 selector activity specifies cortical identity and suppresses hippocampal organizer fate. Science 2008, 319:304-9.

10. Galceran J, Miyashita-Lin EM, Devaney E, Rubenstein JL, Grosschedl R: Hippocampus development and generation of dentate gyrus granule cells is regulated by LEF1. Development 2000, 127:469-82.

11. Lee SM, Tole S, Grove E, McMahon AP: A local Wnt-3a signal is required for development of the mammalian hippocampus. Development 2000, 127:457-67.

12. Shimogori $T$, Banuchi $V, N g$ HY, Strauss JB, Grove EA: Embryonic signaling centers expressing BMP, WNT and FGF proteins interact to pattern the cerebral cortex. Development 2004, 131:5639-47. 
13. Takahashi H, Liu FC: Genetic patterning of the mammalian telencephalon by morphogenetic molecules and transcription factors. Birth Defects Res $C$ Embryo Today 2006, 78:256-66.

14. Wilson L, Maden M: The mechanisms of dorsoventral patterning in the vertebrate neural tube. Dev Biol 2005, 282:1-13.

15. Fukuchi-Shimogori T, Grove EA: Neocortex patterning by the secreted signaling molecule FGF8. Science 2001, 294:1071-4.

16. Storm EE, Garel S, Borello U, Hebert JM, Martinez S, McConnell SK, Martin GR, Rubenstein JL: Dose-dependent functions of Fgf8 in regulating telencephalic patterning centers. Development 2006, 133:1831-44.

17. Hayhurst M, McConnell SK: Mouse models of holoprosencephaly. Curr Opin Neurol 2003, 16:135-41.

18. Monuki ES: The morphogen signaling network in forebrain development and holoprosencephaly. J Neuropathol Exp Neurol 2007, 66:566-75.

19. Muenke M, Beachy PA: Genetics of ventral forebrain development and holoprosencephaly. Curr Opin Genet Dev 2000, 10:262-9.

20. Litingtung Y, Chiang C: Specification of ventral neuron types is mediated by an antagonistic interaction between Shh and Gli3. Nat Neurosci 2000 3:979-85.

21. Rallu M, Machold R, Gaiano N, Corbin JG, McMahon AP, Fishell G: Dorsoventral patterning is established in the telencephalon of mutants lacking both Gli3 and Hedgehog signaling. Development 2002, 129:4963-74.

22. Rash BG, Grove EA: Patterning the dorsal telencephalon: a role for sonic hedgehog? J Neurosci 2007, 27:11595-603.

23. Kiecker $C$, Lumsden $A$ : Hedgehog signaling from the $Z \mathbf{L I}$ regulates diencephalic regional identity. Nat Neurosci 2004, 7:1242-9.

24. Feng J, Bi C, Clark BS, Mady R, Shah P, Kohtz JD: The Evf-2 noncoding RNA is transcribed from the Dlx-5/6 ultraconserved region and functions as a Dlx-2 transcriptional coactivator. Genes Dev 2006, 20:1470-84.

25. Feng J, White B, Tyurina OV, Guner B, Larson T, Lee HY, Karlstrom RO, Kohtz JD: Synergistic and antagonistic roles of the Sonic hedgehog Nand C-terminal lipids. Development 2004, 131:4357-70.

26. Gaiano N, Kohtz JD, Turnbull DH, Fishell G: A method for rapid gain-offunction studies in the mouse embryonic nervous system. Nat Neurosci 1999, 2:812-9.

27. Kohtz JD, Baker DP, Corte G, Fishell G: Regionalization within the mammalian telencephalon is mediated by changes in responsiveness to Sonic Hedgehog. Development 1998, 125:5079-89.

28. Kohtz JD, Lee HY, Gaiano N, Segal J, Ng E, Larson T, Baker DP, Garber EA, Williams KP, Fishell G: N-terminal fatty-acylation of sonic hedgehog enhances the induction of rodent ventral forebrain neurons. Development 2001, 128:2351-63.

29. Lee J, Platt KA, Censullo P, Ruiz i Altaba A: Gli1 is a target of Sonic hedgehog that induces ventral neural tube development. Development 1997, 124:2537-52.

30. Goodrich LV, Johnson RL, Milenkovic L, McMahon JA, Scott MP: Conservation of the hedgehog/patched signaling pathway from flies to mice: induction of a mouse patched gene by Hedgehog. Genes Dev 1996, 10:301-12.

31. Marigo V, Davey RA, Zuo Y, Cunningham JM, Tabin CJ: Biochemical evidence that patched is the Hedgehog receptor. Nature 1996, 384:176-9.

32. Stone DM, Hynes M, Armanini M, Swanson TA, Gu Q, Johnson RL, Scott MP, Pennica D, Goddard A, Phillips $H$, et al: The tumour-suppressor gene patched encodes a candidate receptor for Sonic hedgehog. Nature 1996, 384:129-34.

33. Huang $X$, Litingtung $Y$, Chiang C: Ectopic sonic hedgehog signaling impairs telencephalic dorsal midline development: implication for human holoprosencephaly. Hum Mol Genet 2007, 16:1454-68.

34. Chiang $C$, Litingtung $Y$, Lee E, Young KE, Corden JL, Westphal H, Beachy PA: Cyclopia and defective axial patterning in mice lacking Sonic hedgehog gene function. Nature 1996, 383:407-13.

35. Bai CB, Auerbach W, Lee JS, Stephen D, Joyner AL: Gli2, but not Gli1, is required for initial Shh signaling and ectopic activation of the Shh pathway. Development 2002, 129:4753-61.

36. Park HL, Bai C, Platt KA, Matise MP, Beeghly A, Hui CC, Nakashima M, Joyner AL: Mouse Gli1 mutants are viable but have defects in $\mathrm{SHH}$ signaling in combination with a Gli2 mutation. Development 2000, 127:1593-605.

37. Ohkubo $Y$, Chiang $C$, Rubenstein $J$ : Coordinate regulation and synergistic actions of BMP4, SHH and FGF8 in the rostral prosencephalon regulate morphogenesis of the telencephalic and optic vesicles. Neuroscience 2002, 111:1-17.

38. Hynes M, Ye W, Wang K, Stone D, Murone M, Sauvage F, Rosenthal A: The seven-transmembrane receptor smoothened cell-autonomously induces multiple ventral cell types. Nat Neurosci 2000, 3:41-6.

39. Echelard Y, Epstein DJ, St-Jacques B, Shen L, Mohler J, McMahon JA, McMahon AP: Sonic hedgehog, a member of a family of putative signaling molecules, is implicated in the regulation of CNS polarity. Cell 1993, 75:1417-30.

40. Huang $X$, Litingtung $Y$, Chiang C: Region-specific requirement for cholesterol modification of sonic hedgehog in patterning the telencephalon and spinal cord. Development 2007, 134:2095-105.

41. Li Y, Zhang H, Litingtung Y, Chiang C: Cholesterol modification restricts the spread of Shh gradient in the limb bud. Proc Natl Acad Sci USA 2006, 103:6548-53.

42. Shiota K, Yamada S, Komada M, Ishibashi M: Embryogenesis of holoprosencephaly. Am J Med Genet A 2007, 143A:3079-87.

43. Barkovich AJ, Quint DJ: Middle interhemispheric fusion: an unusual variant of holoprosencephaly. AJNR Am J Neuroradiol 1993, 14:431-40.

44. Cheng X, Hsu CM, Currle DS, Hu JS, Barkovich AJ, Monuki ES: Central roles of the roof plate in telencephalic development and holoprosencephaly. J Neurosci 2006, 26:7640-9.

45. Simon EM, Hevner RF, Pinter JD, Clegg NJ, Delgado M, Kinsman SL, Hahn JS, Barkovich AJ: The middle interhemispheric variant of holoprosencephaly. AJNR Am J Neuroradiol 2002, 23:151-6.

46. Zeltser LM: Shh-dependent formation of the ZLI is opposed by signals from the dorsal diencephalon. Development 2005, 132:2023-33.

47. Vieira C, Martinez S: Sonic hedgehog from the basal plate and the zona limitans intrathalamica exhibits differential activity on diencephalic molecular regionalization and nuclear structure. Neuroscience 2006, 143:129-40.

48. Tian $\mathrm{H}$, Jeong J, Harfe BD, Tabin CJ, McMahon AP: Mouse Disp1 is required in sonic hedgehog-expressing cells for paracrine activity of the cholesterol-modified ligand. Development 2005, 132:133-42.

49. Liu A, Joyner AL, Turnbull DH: Alteration of limb and brain patterning in early mouse embryos by ultrasound-guided injection of Shh-expressing cells. Mech Dev 1998, 75:107-15.

50. Snyder EY, Deitcher DL, Walsh C, Arnold-Aldea S, Hartwieg EA, Cepko CL: Multipotent neural cell lines can engraft and participate in development of mouse cerebellum. Cell 1992, 68:33-51.

51. Olsson M, Campbell K, Turnbull DH: Specification of mouse telencephalic and mid-hindbrain progenitors following heterotopic ultrasound-guided embryonic transplantation. Neuron 1997, 19:761-72.

52. Schaeren-Wiemers N, Gerfin-Moser A: A single protocol to detect transcripts of various types and expression levels in neural tissue and cultured cells: in situ hybridization using digoxigenin-labelled cRNA probes. Histochemistry 1993, 100:431-40.

53. Tekki-Kessaris N, Woodruff R, Hall AC, Gaffield W, Kimura S, Stiles CD, Rowitch DH, Richardson WD: Hedgehog-dependent oligodendrocyte lineage specification in the telencephalon. Development 2001, 128:2545-54.

doi:10.1186/1471-213X-10-118

Cite this article as: Himmelstein et al:: Balanced Shh signaling is

required for proper formation and maintenance of dorsal telencephalic midline structures. BMC Developmental Biology 2010 10:118. 